The Significance of Seniority for Women Managers' Interpretations of Organizational Restructuring

\author{
Ruth Simpson \\ Brunel University \\ School of Business and Management \\ Uxbridge \\ UB8 3PH \\ UK \\ Email: r.simpson@brunel.ac.uk \\ Debbie Holley \\ London Metropolitan University \\ Adrian Woods \\ Brunel University
}




\title{
The Significance of Seniority for Women Managers' Interpretations of Organizational Restructuring
}

\begin{abstract}
This paper examines the impact of restructuring within the transport and logistics sector on women managers working at senior and less senior (middle/junior management) levels of the organization. The majority of women experienced increased performance pressures and heavier workloads as well as an increase in working hours. At the same time, there were pressures to work at home (i.e. week-ends and evenings) and reduced opportunities to work from home (i.e. during normal office hours). Management level emerged as an important factor in how these changes were interpreted. Senior managers perceived more positive outcomes in terms of increased motivation and loyalty. Despite a longer working week, they were less likely to report low morale as an outcome from long hours. In fact, irrespective of management level, women working shorter hours were more likely to report low morale as an outcome. Results are discussed in relation to literature on restructuring and careers, in terms of perceptual framing and in relation to different levels of investment in the organization.
\end{abstract}

Key words: restructuring, gender, management level, morale 


\section{Introduction}

This article presents the findings of a survey of 75 women transport and logistics managers which explored the impact of restructuring on various organizational and work practices at senior and less senior management levels. Transport and logistics were chosen as sectors that have undergone considerable restructuring in the UK over the last few years (Glover, 2002; Richardson, 1999) while, at the same time, attracting more women in both in a managerial and a non-managerial capacity (Clarke, 1999). While extensive research on restructuring has highlighted implications for working hours, work practices and careers (e.g. IM, 1996; Wajcman, 1996; Lockwood et al, 1992; Benbow, 1996; Cooper, 1998) and while some research has indicated more positive perceptions of restructuring at higher management levels (e.g. Worrall and Cooper, 1999; Rotondo, 1999; McKinley and Scherer, 2000), the impact on women as well as the significance of their hierarchical position has received less attention. This paper addresses the above research gap.

\section{Recent Research}

As Mosca (1997), Herriot (1998) and Baruch and Hind (1999) indicate, restructuring is now a routine and permanent feature of organizational life with profound implications for the nature of managerial work. The IM-UMIST Quality of Working Life Surveys (Worrall and Cooper, 1997; 1998) revealed that nearly two out of every three managers from a cohort of 5,000 had experienced major restructuring in the two years surveyed and that three quarters worked in excess of their contract hours each week. Similarly, research by McKay (1995) has indicated that longer working hours, increased workloads and radically altered responsibilities frequently follow a restructuring programme. In the NHS, for example, prolonged change meant many 
managers were working an average 56 hours a week (IHSM, 1994) while at BT (British Telecom), the number of employees working more than 46 hours a week increased from $39 \%$ to $51 \%$ following a massive restructuring programme (Newell and Dopson, 1996). Similar results emerged from two Institute of Management (IM) surveys: $80 \%$ of senior managers and $75 \%$ of middle managers were found to have been personally affected by restructuring in terms of increased workloads and responsibilities (Lockwood et al, 1992; Benbow, 1996). As Collinson and Collinson (1997) indicate from their study of restructuring and downsizing in the UK insurance industry, managers who survived redundancy had to work longer hours to process the increased amounts of information and data on their desks as they coped with new and larger areas of responsibility. At the same time, many managers were driven by the insecurity and uncertainty surrounding change to demonstrate visible commitment to the job by staying at the office longer than was strictly necessary. At BT, for example, visible commitment was often cited as a key factor in terms of improved career chances so that an important measure of success was the number of hours worked despite the fact that there was a strong feeling that these extra hours were not really necessary (Newell and Dopson, 1996).

One impact of these changes has been a marked increase in stress and stress related illnesses (IM, 1996; Cooper, 1998) as managers cope with the pressures and uncertainties of change as well as with the conflicting demands of work and personal lives (two thirds of male and female managers in the IM survey claimed they had not achieved a good balance between work and home). Similarly, the IM-UMIST Quality of Working Life Surveys (Worrall and Cooper, 1997; 1998) found that restructuring had a profound adverse effect on loyalty, morale, motivation and perceived job security. Other work (e.g. Sparrow, 2000) has pointed to the detrimental effects of restructuring on the psychological contract i.e. the explicit and implicit relationship of mutual 
expectations between managers and their employing organisations (Rousseau, 1990). Flatter organizations and reduced promotion opportunities through the dismantling of traditional career ladders weaken a contract that may well be premised on upward mobility and which, as Turnley and Feldman (1999) suggest, is likely to lead to increased exit and decreased loyalty to the company. However, as Worrall and Cooper found, some of these detrimental effects may be mediated to some extent by management level with senior personnel interpreting the changes more favourably than those less senior. In their study, Chairmen (sic), Chief Executive Officers (CEO's) and Managing Directors (MDs) were much more likely than other managers to feel that restructuring had increased their morale, motivation and their loyalty and, similarly, senior managers were more likely than middle and junior managers to feel this way (Worrall and Cooper, 1999).

Few of the above studies focused specifically on women in examining the impact of restructuring. Research on women managers by Simpson and Holley (2001) suggests some support for Worrall and Cooper's study above: senior women in their study were more likely than junior counterparts to perceive restructuring as beneficial in terms of enhancing promotion opportunities and creating a more women friendly environment. Most other studies that address gender differences, however, suggest that irrespective of level women are particularly vulnerable during times of organizational change. This can occur through the incorporation of female dominated functions (training, marketing, HR) into general management and through the reduction of middle management and supervisory posts where many women are located (Woodall et al, 1997; Collinson and Collinson, 1997; Simpson, 1998). 
All these factors have particular implications for women transport and logistics managers. Firstly, these sectors have undergone considerable change over the last decade. In transport, competitive pressures associated with globalisation, marketization and privatisation have seen a change from old bureaucratic paternalism in the public sector and from rigid chains of command associated with military models within the private sector to an emphasis on value for money and flexibility (Shaw, 1993). In logistics, globalisation and competitive pressures over costs and time have forced many organisations to restructure their operations. Transport and logistics, therefore, have been characterised by wide scale restructuring and cultural change. Secondly, while men still dominate senior positions in both sectors (Clarke, 1999; Richardson, 1999) and while evidence exists of substantial career barriers to women's progression (Lynagh et al, 1999), the number of women is increasing so that they now account for approximately $26 \%$ of the workforce (Clarke, 1999). The growing proportion of women in these sectors, therefore, combined with the context of restructuring and change makes their experiences a fruitful focus of inquiry.

\section{Research Aims}

Against this background, the project set out to explore the effects of restructuring on women managers in the transport and logistics sectors and to assess the extent to which these effects were influenced by management level. Based on the above literature, we framed the following hypothesis:

Senior women managers are likely to perceive the outcomes of restructuring more positively than less senior managers.

Senior managers were taken to include categories of director, partner and senior manager. Twenty four women identified themselves as senior managers in this way (32\% of the total). Less senior managers were taken to include middle managers, junior managers and 
professional/technical staff. Fifty one women identified themselves as less senior managers (68\% of the total).

\section{Method and Sample}

One hundred and seventy questionnaires were sent out in May 1999 to UK women transport managers via the Women's Transport Network and to logistics managers via the Institute of Logistics. A total of 75 completed questionnaires were returned making a response rate of $44 \%$. Effects of restructuring were measured on seven point Lickert scale and included 14 items such as promotion prospects, autonomy, motivation and loyalty. In each case respondents were asked to identify any change that has resulted from restructuring as positive (extreme case 7) to negative (extreme case 1). Table 1 includes all 14 items and average scores. Respondents were also asked about working hours and the possible impact of long working hours on a range of items including health problems, stress, low morale and reduced productivity. Where appropriate, either the F. test or the Chi-square test was used to explore significant differences between the responses of senior managers and less senior managers.

\section{Results}

\section{$\underline{\text { Work Practices, Motivation and Loyalty }}$}

Restructuring had the greatest impact on performance pressures, followed by longer working hours and the need to take work home in the evening. This coincided with a reduced opportunity to work from home. Senior managers were more likely to report an increase in both motivation and loyalty to the company as a consequence of the restructuring while less senior managers experienced a decrease. At the same time, senior managers were more likely to perceive an increase in autonomy $(\mathrm{P}=0.057)$ and better communication up and down the organization $(\mathrm{P}=$ 
$0.054)$ compared with less senior managers. The latter two were significant at $10 \%$ level. Table 1 summarizes these results.

Take in Table 1 here

\section{$\underline{\text { Working Hours }}$}

Not surprisingly, a significant difference emerged between the average working week of senior and less senior managers $(\mathrm{P}=0.001)$. Women managers as a whole worked an average of 48 hours a week with senior managers working 52.5 hours and less senior 44.5 hours. However, despite working longer hours, there was no difference in satisfaction with hours worked between the two management levels. Over a third of respondents were dissatisfied with the hours they worked and three quarters felt that long hours was an issue of concern. Of these, over half felt that long hours led to problems with stress and reduced social time while over a third felt it damaged their relationship with their partner and reduced their productivity. Forty four percent identified stress as the single most important issue connected with long hours.

A significant difference emerged with respect to low morale by management level. Despite working fewer hours, less senior managers were significantly more likely to identify low morale as an issue arising from long hours (35.3\%) than senior managers (12.5\%). In fact, of those who chose low morale as an outcome, only $16 \%$ were senior managers compared with $50 \%$ of less senior managers $(P=0.012$, Chi square: 6.167).

Take in Table 2 here 
Overall, irrespective of seniority, identification of low morale as an outcome was associated with fewer hours being worked. In other words, whatever their level, women working fewer hours were more likely to identify low morale and, as hours increased, to find low morale less of a problem. This group (long hours an issue, low morale an outcome) worked fewer hours on average (42.7 hours) than those who reported long hours as an issue but not in terms of low morale (51.5 hours). This is illustrated by the following table based on an analysis of seniority, hours worked and identification of low morale as an issue. Results suggest that both senior and less senior managers are less likely to identify low morale as hours increase.

\section{Take in Table 3 here}

Looking at the association between low morale and stress, we found that while less senior managers were likely to report low morale and stress as issues arising from long hours, senior managers were more likely to report stress on its own (i.e. did not identify low morale). For example, as Table 4 illustrates, of those senior managers who reported that long hours were leading to some problem, $52.6 \%$ said they were stressed but they did not have low morale. On the other hand for less senior managers only a third (32.4\%) so reported.

Take in Table 4 here

Not surprisingly, those who were stressed and with low morale were significantly more likely than the other two categories (stressed but not low morale, not stressed and no low morale) to report health problems $(\mathrm{P}=0.075$, Chi square: 5.190).

\section{Discussion}

Results suggest some support for the hypothesis as set out above. Senior managers were more 
likely to interpret the result of restructuring as beneficial in terms of increased motivation and loyalty, increased autonomy and greater communication up and down the organization. Despite working longer hours than their less senior counterparts, they were equally satisfied (or dissatisfied) with hours worked though, interestingly, they were less likely to experience low morale as a result.

This conforms to earlier work by Simpson and Holley (2001), which found that senior women managers were more positive about the effects of restructuring and perceived fewer barriers to career advancement than junior counterparts. This, they felt, reflected greater opportunities at senior management level as new responsibilities were made available and as entrenched attitudes, detrimental to women, were challenged by the climate of change. Similar outcomes also emerged in the IM-UMIST Quality of Working Life Survey (Worrall and Cooper, 1997; 1998) where restructuring was more likely to be associated with lowered morale and an erosion of motivation and loyalty at lower rather than higher managerial levels.

Various explanations can be proposed for this trend. The probable involvement of senior personnel in strategic decision-making concerning restructuring may well mean more personal commitment to the restructuring process at this level. Top managers may therefore be more accepting of the outcomes than people lower down the hierarchy. In a similar vein, McKinley and Scherer (2000) argue that restructuring can result in a reduction of uncertainty or a state of 'cognitive order' for senior personnel - particularly where change takes place in a turbulent environment. Under these conditions, internal structural change matches the level of change in the environment leading to a sense of 'fit' between internal structure and the outside world. However, this 'cognitive order' may not be shared by workers lower down the hierarchy who 
experience disruptions in established business processes and the opening up of alternative and less familiar ways of getting work done. A further explanation is proposed by Rotondo (1999) who suggests that the elimination of hierarchical career paths contributes to a 'career plateau' where careers stall before senior management level. It is therefore mid-career employees who are most adversely affected by downsizing and restructuring. In terms of the psychological contract, reduced opportunities for advancement may then lead to perceptions of violation of the contract a common outcome, as Turnley and Feldman (1999) suggest, in restructured organizations. Under these circumstances, perceptions of 'over-investment' in the organization may become widespread and employees are likely to reassess their basic attachment to the job (Sparrow, 1998). The dissatisfaction with hours worked, together with lower levels of loyalty and motivation on the part of less senior personnel, may be symptomatic of such perceptions.

These factors may go some way to explain the more positive perception of restructuring on the part of senior personnel. They may also partly explain the tendency for less senior managers (though working fewer hours than more senior counterparts) to identify low morale as an outcome from long working hours. One possibility here is that altered areas of responsibility from restructuring give senior personnel a challenge which they find stimulating, despite the long hours associated with such change. At the same time, seniority and the performance of senior roles may carry morale boosting intrinsic rewards - e.g. of autonomy and of decision making which are not shared further down the hierarchy. The trend for senior managers to perceive an increase in autonomy, as well as better communication, may be indicative of this effect.

An alternative explanation relates to perceptual framing. This suggests that workers, although actually affected by a change, report only minor adjustments to their perception of what is 
happening. On this basis, the different perceptions of senior and less senior managers to the effects of long hours may be explained by different perceptual frames. As Hulin and Glomb (1999) point out, if the employee's frame was anchored in the context of no work, then even irregular work and income can be viewed positively. In this context, if senior managers have always put in long hours to reach their position, then long hours associated with restructuring will not be interpreted as negatively as those people lower down the hierarchy for whom long hours may be a new phenomenon.

Not all effects of restructuring were related to managerial level. Irrespective of their position in the hierarchy, and in accordance with Worrall and Cooper's study, restructuring was associated with a greater pressure to take work home in the evenings. At the same time there was a reduced opportunity to work from home. This suggests an important distinction between working at home and working from home (Sparrow, 2000). On this basis, managers may need to work at home to cover increased workloads (i.e. evenings and week-ends) but have less opportunity to work from home (i.e. during normal office hours). This may reflect a move towards more inflexible work practices on the part of organizations. Alternatively it may reflect an imperative on the part of managers to place themselves in a favourable position in terms of job security and/or promotion through increased presence at work - thereby demonstrating visible commitment to the job. This trend towards 'presenteeism' has been corroborated by other studies (e.g. Cooper, 1999; Collinson and Collinson, 1997; Simpson, 1998).

For the majority of women managers, irrespective of level, restructuring was associated with performance pressures and long working hours - with stress and reduced social time as common outcomes. Similar issues emerged from Worrall and Cooper's study where long hours led to 
stress and to problems in relationships with partners and children. However, while Worrall and Cooper found an association between long hours, stress and reduced morale, in this study, women working longer hours were less likely to report low morale than women working shorter hours. At the same time, it was possible to feel stress from long hours but have no problems with morale - suggesting that long hours and stress may not always be associated with negative outcomes. The possibility of other (more positive) results from long working hours may reflect intrinsic benefits accruing from greater levels of investment in the organization. As Hochschild (2000) points out, the meaning of work is changing. People invest more time and energy in the workplace and it is in this, rather than the non-work arena, where identity, challenge and self expression are increasingly sought. On this basis, feelings of self fulfilment, together with associated improvements in morale, are likely to increase as more time is spent at work.

\section{Conclusion and Limitations of the Research}

Restructuring is likely to be an on-going process in transport and logistics as well as in other sectors of the economy, involving diverse changes to the nature of work. Adverse effects of restructuring on workloads and work practices as well as the detrimental implications of long working hours for morale, stress and productivity have been well documented. This paper has contributed to our understanding of how such changes impact on women managers and suggests a more complicated picture. Not only is management level an important predictor of the positive or negative perceptions of restructuring and of perceptions of working hours on morale but long hours on its own may not be as detrimental to morale as first thought. In other words, it may not be the number of hours worked that is important but how this is interpreted. The nature of that interpretation may well depend on management level, on different perceptual frames or on different levels of investment in the organization. 
This research and the subsequent interpretation of findings have several limitations. Firstly, the project was based on a sample of women managers. The extent to which these findings relate specifically to women - or whether they would apply more generally to men - can therefore not be ascertained from this study alone. One possibility is that senior women managers, who have overcome considerable odds to reach top management positions, accordingly perceive more benefits from their status, despite changes brought by restructuring and despite long hours, than would men. In other words, based on their expectations and past experiences, women may interpret changes from restructuring in different ways. More research, which is able to make comparisons between men and women, may help to determine the extent to which these results apply in a more general context. A second issue relates the small sample size (75 women). This may have compromised the reliability of the results and have implications for generalisability. Finally, the sample was drawn from just two sectors: transport and logistics. Further research in different settings would enable a more comprehensive picture to emerge on this important area of study and allow the conclusions drawn to be more fully substantiated. 


\section{References}

Baruch, Y. and Hind, P. (1999), "Perpetual Motion in Organizations: Effective Management and the Impact of the New Psychological Contract on 'Survivor Syndrome'”, European Journal of Work and Organizational Psychology, Vol 8 No. 2, pp.295-306

Benbow, N. (1996), "Survival of the Fittest: A Survey of Managers' Experience of and Attitudes to Work in the Post Recession Economy", Institute of Management, Corby

Clarke, S. (1994) Presentees: New Slaves of the Office who run in Fear, Sunday Times, 16 Oct

Clarke, N. (1999) “Breaking Barriers”, Motor Transport, February

Collinson, D. and Collinson, M. (1997) "Delayering Managers: Time Space Surveillance and its Gendered Effects”, Organization, Vol 4 no. 3 pp375-407

Cooper, C. (1999) “The Changing Psychological Contract at Work”, European Business Journal, Vol 11 no. 3, pp115-117

Ely, R. (1994) “The Social Construction of Relationships among Professional Women at Work" in M. Davidson and R. Burke (eds) Women in Management: Current Research Issues, London: Chapman

Feldman, D. (1996) "Managing Careers in Downsizing Firms", Human Resource Management, Vol. 35, pp.145-162

Glover, J. (2002) "Restructuring the Railway Industry", Logistics and Transport Focus, Vol 4 No. pp. 39-47

Herriot, P. (1998) "The Role of the HRM Function in Building a New Proposition for Staff", in Sparrow, P. and Marchington, M. (eds) Human Resource Management: The New Agenda, Financial Times: Pitman

Holley, D. (1998) “Corporate Woman: Moving on and Moving Up?”, University of North London Working Paper, Sept.

Hochschild, A.(2001) "The Time Bind: When Work becomes Home and Home becomes Work", Owl Books, New York

Hulin, C. and Glomb, T. (1999) "Contingent Employees: Individual and Organizational Considerations", in Ilgen, D. and Pulakos, E. (eds) The Changing Nature of Performance: Implications for Staffing, Motivation and Development, Jossey-Bass, san Francisco 
IHSM Consultants (1994) "Creative Career Paths in the NHS", Report No. 1 - Top Managers. Study conducted for the NHS Women's Unit, NHS Executive, London

IM (1996) “Are Managers Under Stress ?: A Survey of Management Morale”, Institute of Management, Corby

Kanter R (1977), Men and Women of the Corporation, New York Basic Books

Lockwood, J. Teevan, P. and Walters, M. (1992) “Who's Managing the Managers? The Reward and Career Development of Middle Managers in a Flat Organization", Institute of Management, Corby.

Lynagh, P. Murphy, P. \& Poist, R. (1999) "Career Perspectives of Women in Distribution: Congruency or Contrast?", International Journal of Physical Distribution and Logistics Management, Vol 29 No 3 pp192-206

McKay, S. (1995) "Workplace Culture, High Stress", Report of a seminar by the National Women's Commission

Mosca, J. (1997) “The Restructuring of Jobs for the Year 2000”, Public Personnel Management, Vol 26 No.1, pp. 43-60

Newell, H.and Dobson, S. (1996) "Muddle in the Middle: Organizational Restructuring and Middle Management Careers", Personnel Review, Vol 25 No. 4, pp.35-48

Richardson, H. (1999) “Women Lead in Style”, Transportation and Distribution, April

Rotondo, D. (1999) "Individual-difference Variables and Career-related Coping", Journal of Social Psychology, Vol 139 No.4, pp. 458 - 472

Rousseau, D, (1990), "New Hire Perceptions of their own and their Employer's Obligations: A Study of Psychological Contracts", Journal of Organizational Behaviour, Vol 11, pp.389400

McKinley, W. And Scherer, A. (2000) "Some Unanticipated Consequences of Organizational Restructuring", Academy of Management Review, Vol. 25 (4): 735- 752

Shaw, S. (1993) Transport: Strategy and Policy. Blackwell,, Oxford.

Simpson, R, (1998) "Presenteeism, Power and Organisational Change: Long Hours as a Career Barrier and the Impact on the Working Lives of Women Managers", British Journal of Management, Vol 9 pp. 37-50

Sparrow, P. (2000) "New Employee Behaviours, Work Designs and Forms of Work: what is in store for the future of work?", Journal of Managerial Psychology, Vol.15, No.3, pp. 207219 
Sparrow, P. (1998) "Reappraising Psychological Contracting: Lessons for the Field of Human Resource Development from Cross-cultural and Occupational Psychology Research", International Studies of Management and Organization, Vol 28, No.1, pp. 30-54

Turnley, W. and Feldman,. D. (1999) "The Impact of Psychological Contract Violations on Exit, Voice and Neglect", Human Relations, Vol.52, No.7, pp. 895-913

Wajcman, J. (1996) "Women and Men Managers: Careers and Equal Opportunities" in Crompton, R., Gallie D. and Purcell, K. (eds) Changing Forms of Employment, Routledge London pp.259-77

Woodall, J., Edwards, C. and Welchman, R. (1997) "Organisational Restructuring and the Achievement of an Equal Opportunity Culture", Gender Work and Organization, Vol 4 No1 pp2-12

Worrall, L. and Cooper, C. (1997) "Quality of Working Life 1998 Survey of Managers' Changing Experiences", London: Institute of Management

Worrall, L. and Cooper, C. (1998) "Quality of Working Life 1998 Survey of Managers' Changing Experiences". London: Institute of Management 
Table 1: Impact of Restructuring by Management Level

\begin{tabular}{|l|r|r|r|l|}
\hline & $\begin{array}{l}\text { Mean } \\
\text { senior } \\
\text { manager }\end{array}$ & $\begin{array}{l}\text { Mean less } \\
\text { senior } \\
\text { manager }\end{array}$ & $\begin{array}{l}\text { Mean } \\
\text { All }\end{array}$ & $\begin{array}{l}\text { F statistic and } \\
\text { significance }\end{array}$ \\
\hline Performance pressures & 5.36 & 5.47 & 5.43 & \\
\hline Long hours & 5.31 & 4.86 & 5.01 & \\
\hline Work in the evening & 5.22 & 4.72 & 4.90 & \\
\hline Customer focus & 5.00 & 4.78 & 4.85 & \\
\hline Work load & 4.81 & 4.27 & 4.46 & \\
\hline Team working & 4.59 & 4.13 & 4.29 & \\
\hline Autonomy & 4.57 & 3.64 & 3.98 & $3.767 \mathrm{P}=0.057$ \\
\hline Communication up and down the organisation & 4.50 & 3.71 & 3.97 & $3.836 \mathrm{P}=0.054$ \\
\hline Flexible hours & 3.57 & 3.46 & 3.50 & \\
\hline Motivation & 4.36 & 3.00 & 3.45 & $8.269 \mathrm{P}=0.005$ \\
\hline Promotional prospects & 3.85 & 2.95 & 3.25 & \\
\hline Loyalty to company & 4.00 & 2.81 & 3.21 & $7.145 \mathrm{P}=0.010$ \\
\hline Job security & 3.22 & 2.65 & 2.85 & \\
\hline Working from home & 2.95 & 2.47 & 2.64 & \\
\hline
\end{tabular}

Table 2: Impact of long working hours by management level (\%)

\begin{tabular}{|l|l|l|l|}
\hline & $\begin{array}{l}\text { Senior } \\
\text { Manager }\end{array}$ & $\begin{array}{l}\text { Less senior } \\
\text { manager }\end{array}$ & Total \\
\hline Health problems & 37.5 & 39.2 & 38.7 \\
\hline Stress & 54.2 & 54.9 & 54.7 \\
\hline Low morale & 12.5 & 35.3 & 28.0 \\
\hline Reduced productivity & 20.8 & 35.3 & 30.7 \\
\hline Problems with relationship with partner & 33.3 & 37.3 & 36.0 \\
\hline Problems with relationship with children & 16.7 & 23.5 & 21.3 \\
\hline Childcare problems & 12.5 & 11.8 & 12.0 \\
\hline Reduced social time & 50.0 & 56.9 & 54.7 \\
\hline $\mathbf{N}$ & 24 & 51 & 75 \\
\hline
\end{tabular}

$* \mathrm{P}=0.030$ 
Table 3: Percentage of those managers perceiving low morale to be an issue arising from long working hours by seniority and by hours worked (\%)

\begin{tabular}{|l|l|l|l|l|}
\hline & $\begin{array}{l}\text { Less senior } \\
\text { managers (under } \\
\mathbf{5 0} \text { hours) }\end{array}$ & $\begin{array}{l}\text { Less senior } \\
\text { managers (over 50 } \\
\text { hours) }\end{array}$ & $\begin{array}{l}\text { Senior managers } \\
\text { (under 50 hours) }\end{array}$ & $\begin{array}{l}\text { Senior managers } \\
\text { (over 50 hours) }\end{array}$ \\
\hline $\begin{array}{l}\text { Low morale an } \\
\text { issue }\end{array}$ & 54.2 & 41.7 & 20.0 & 14.3 \\
\hline $\mathbf{N}$ & 24 & 12 & 5 & 14 \\
\hline
\end{tabular}

$\mathrm{P}=0.080$, Chi square: 6.747

Table 4: Percentage of managers identifying stress and low morale by management level (\%)

\begin{tabular}{|l|l|l|}
\hline & Senior manager & Less senior manager \\
\hline Stressed, low morale & 15.8 & 47.1 \\
\hline Stressed, no low morale & 52.6 & 32.4 \\
\hline Not stressed, no low morale & 31.6 & 20.6 \\
\hline
\end{tabular}

$\mathrm{P}=0.073$, Chi square: 5.231

(NB the 2 people reporting no stress, low morale have been removed from the analysis) 